\title{
Validation of a Novel, Objective Measure of Occupational Sitting
}

\author{
Gemma C. Ryde, Nicholas D. Gilson, Alessandro Suppini and Wendy J Brown \\ St Lucia Campus, School of Human Movement Studies, The University of Queensland, Australia
}

\begin{abstract}
Validation of a Novel, Objective Measure of Occupational Sitting: Gemma C. RYDE, et al. St Lucia Campus, School of Human Movement Studies, The University of Queensland, Australia-Objective: To test the validity of a sitting pad (SP) to measure desk based sitting time and transitions, against camera derived direct observation; and to compare the data with those from inclinometers in the $\operatorname{ActivPAL}^{3}(\mathrm{AP})$ and ActiGraph GT3X+(AG). Methods: Australian employees $(n=13$; 9 women; mean age $30 \pm 6.5$ years) were provided with a SP, AG and AP in 2011. A camera recorded chair based transitions during a prescribed and a free living protocol. Mean sitting time and transitions were calculated for each device and intra-class correlations (ICCs) and mean differences between (a) the SP and the camera and (b) the AP, AG and camera, were compared. Results: During the prescribed protocol, the smallest mean differences compared with the camera were for the SP; sitting time $0.30 \pm 0.21$ minutes, transitions $-0.46 \pm 0.78$. During free living, both the SP and AP (set to record events greater than 3 seconds) showed excellent levels of agreement with the camera for sitting time (0.999 and 0.990 respectively) and transitions (0.997 and 0.928 respectively). Agreement between the camera and the AG was poor for both sitting time and transitions ( 0.257 and 0.033 respectively). Conclusions: The SP is a highly accurate measure of desk based sitting time and transitions and provides novel measurement and intervention opportunities for research into occupational sitting.
\end{abstract}

(J Occup Health 2012; 54: 383-386)

Key words: Measurement, Sedentary behaviour, Sitting, Workplace

To date, cross sectional and intervention research on sitting has tended to rely on self report measures ${ }^{1,2)}$. Although these measures are valuable for describing

Received Mar 29, 2012; Accepted May 25, 2012

Published online in J-STAGE Jun 26, 2012

Correspondence to: G. Ryde, School of Human Movement Studies,

The University of Queensland, Brisbane, Qld 4072, Australia (e-mail: g.ryde@uq.edu.au) behavioural trends and assessing emerging relationships between sitting and health, they may not be sufficiently sensitive for detecting changes in sitting time ${ }^{3)}$.

Currently, few devices objectively measure sitting time. Accelerometers are commonly used in sedentary behaviour research, but were developed to measure movement and cannot distinguish between sitting and standing ${ }^{4}$. Devices that measure postural change such as inclinometers, have been suggested as an alternative to accelerometers for the measurement of sitting ${ }^{3,5)}$. However, available devices are expensive, and currently orientated towards data collection for research, rather than day-to-day use by the general population.

Almost half of total daily sitting occurs in the workplace $^{6}$, with modern occupations involving a high volume of desk based tasks. We have developed a low cost, low burden instrument, known as the sitting pad (SP), designed to measure desk based occupational sitting. The aims of this study were therefore (1) to test the validity of the SP as a measure of desk based sitting time and transitions to and from sitting ("transitions"), against camera derived direct observation; and (2) to compare the data with those from inclinometers in the ActivPAL ${ }^{3}$ (AP) and ActiGraph $\mathrm{GT} 3 \mathrm{X}+(\mathrm{AG})$.

\section{Methods}

A convenience sample of 13 healthy office workers were recruited via email and word of mouth; workers were based in the same building situated on a suburban university campus in South-East Australia. Study protocols were approved by the Human Research Ethics Committee of The University of Queensland, Australia.

The SP (Fig. 1) is a prototype device designed by The University of Queensland, Brisbane, to measure desk based sitting time for use in the workplace. It comprises a cushion containing a medical grade pressure sensor $(43 \times 32 \times 2 \mathrm{~cm})$ which acts as a switch 


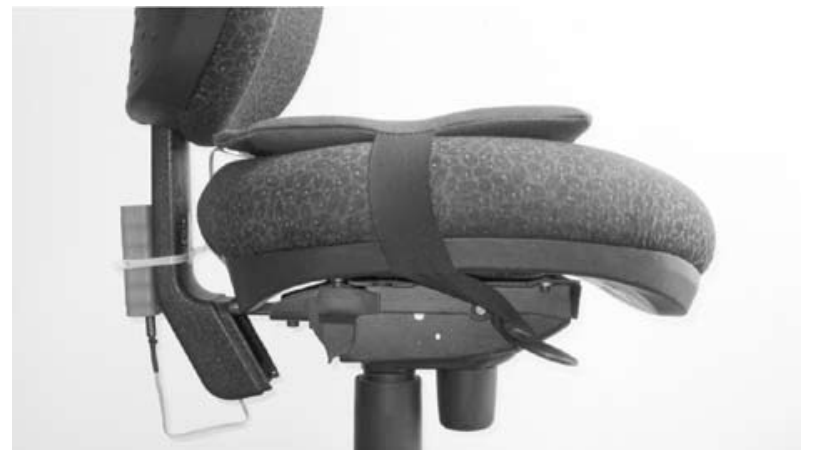

Fig. 1. Side view of the sitting pad on an office chair. Not commercially available (Australia, 2011).

to detect transitions of greater than 3 seconds to and from the seat, and a microcontroller $(11.5 \times 5 \times 3 \mathrm{~cm}$; RF Technology, Brisbane, Australia) which records a time stamp for each transition. Manufacturer and researcher beta testing for sensitivity found 3 seconds to be the most accurate threshold for detecting a transition, with a minimum load of $3 \mathrm{~kg}$ and no biologically plausible maximum load. Data are downloaded using a proprietary software package which produces a Microsoft Excel output for data analysis.

The inclinometers in both the AP and AG detect a change in position based on the angle of the device. APs were programmed to match the SP in terms of recording events greater than three seconds (AP3); we also tested against the device default of ten seconds (AP10). AGs were set at a $30 \mathrm{~Hz}$ sampling rate. Personal office chairs were fitted with a SP and each participant wore an AG and two APs using established procedures $^{7,8)}$. The same devices were used for each participant. A camera was positioned to record movement around the office and chair based transitions to and from sitting.

Two protocols were used. Participants initially followed a directed, standardised protocol of sitting and standing for short periods of $3,5,10,15,20$, 25, 30, 45 and 60 seconds (protocol 1: prescribed). Participants were then left to resume their usual work patterns for up to 60 minutes (protocol 2: free living).

Camera data were viewed and a timeline created with each second binary coded (sitting=0; standing/ moving=1). A change in the binary code $(1-0$ or $0-1)$ was recorded as a transition. Second-by-second inclinometer data were downloaded for the AG. SP and AP data were downloaded with a timestamp for every recorded transition. All data were mapped against the camera derived timeline. AP and AG data were excluded from analyses when the participant was not in view during the free living protocol.

Mean sitting time and transitions were calculated for each device. Intra-class correlations (ICCs) and mean differences between (a) the SP and the camera and (b) the AP3, AP10, AG and camera, were calculated. An ICC value of $\geq 0.90$ was deemed excellent, $0.75-0.89$ good and $\leq 0.74$ poor $^{9)}$.

\section{Results}

Thirteen participants completed the study ( 9 women, 4 men, mean age $30 \pm 6.5$ years). Mean differences in sitting time and transitions, between each device and the camera, are shown in Table 1. During the prescribed protocol, the smallest mean differences in sitting time and transitions compared with the camera were for the SP (Sitting time; $0.30 \pm 0.21$, transitions; $-0.46 \pm 0.78$ ). The largest mean differences in sitting time and transitions compared with the camera were for the AG and AP10 respectively (Sitting time AG; $-1.49 \pm 2.74$, transitions AP10; $-10.08 \pm 2.13$ ). ICCs for sitting time and transitions during the free living protocol are also shown in Table 1. The SP, AP3 and AP10 showed excellent levels of absolute agreement with camera measured sitting time $(0.999,0.990$ and 0.981 respectively), while agreement between the camera and the AG was poor (0.033). For number of transitions, there was excellent agreement between both the SP and AP3 with the camera (0.997 and 0.928 respectively), but the agreement between the $\mathrm{AG}$ and AP10 with the camera was poor $(0.033$ and 0.665 respectively).

To provide detail on the measurement differences for each device, a typical example of data, showing the traces of sitting and standing time during the prescribed protocol, is shown in Fig. 2. The traces from the SP and the camera were almost identical with only a slight delay in the SP's recording of the transition from standing back to sitting. The AP3 mirrored the camera trace accurately with only a slight delay at transitions. The AG detected the initial 3 seconds standing bout, but beyond this, failed to differentiate between sitting and standing.

\section{Discussion}

The findings indicated that the SP and AP3 provided highly accurate measures of desk based sitting time and transitions in both the prescribed and free living protocols. In contrast, the AG inclinometer was unable to accurately measure sitting time or transitions during either protocol.

The accurate measurement of transitions is important given emerging evidence linking breaks in sedentary time and sitting with health indicators, including waist circumference, BMI, triglycerides, 2 hours plasma glucose and C-reactive protein ${ }^{10-12)}$. Findings from the present study indicate that inclinometer derived AG data overestimate sitting transitions. This may be due to small movements when seated or standing 
Table 1. Mean differences between each device and the camera for sitting time and transitions to and from sitting (Australia, 2011)

\begin{tabular}{|c|c|c|c|c|c|c|}
\hline $\begin{array}{l}\text { Measurement } \\
\text { device } \\
(\mathrm{n}=13)\end{array}$ & $\begin{array}{l}\text { Mean sitting } \\
\text { time } \\
\text { (Minutes) }\end{array}$ & $\begin{array}{l}\text { Mean difference } \\
\text { in sitting time } \\
(95 \% \mathrm{CI}) \\
\text { (Minutes) }\end{array}$ & ICC $(95 \% \mathrm{CI})$ & $\begin{array}{l}\text { Mean } \\
\text { transitions } \\
\text { (Number) }\end{array}$ & $\begin{array}{l}\text { Mean difference } \\
\text { in transitions } \\
(95 \% \mathrm{CI}) \\
\text { (Number) }\end{array}$ & ICC $(95 \%$ CI $)$ \\
\hline \multicolumn{7}{|l|}{$\begin{array}{l}\text { Protocol } 1 \\
\text { Prescribed }\end{array}$} \\
\hline Camera & $5.01 \pm 0.16$ & - & - & $29.92 \pm 0.28$ & - & - \\
\hline SP & $5.31 \pm 0.19$ & $\begin{array}{c}0.30 \pm 0.21 \\
(-0.38 \text { to } 0.44)\end{array}$ & - & $29.46 \pm 0.78$ & $\begin{array}{l}-0.46 \pm 0.78 \\
(-1.99 \text { to } 1.07)\end{array}$ & - \\
\hline AP3 & $4.52 \pm 0.57$ & $\begin{array}{l}-0.49 \pm 0.59 \\
(-1.65 \text { to } 0.67)\end{array}$ & - & $21.46 \pm 5.73$ & $\begin{array}{l}-8.46 \pm 5.83 \\
(-19.89 \text { to } 2.97)\end{array}$ & - \\
\hline AP10 & $4.13 \pm 0.39$ & $\begin{array}{r}0.88 \pm 0.39 \\
(0.03 \text { to } 1.73)\end{array}$ & - & $19.85 \pm 2.12$ & $\begin{array}{l}-10.08 \pm 2.13 \\
(-14.72 \text { to }-5.44)\end{array}$ & - \\
\hline AG & $3.52 \pm 2.78$ & $\begin{array}{c}-1.49 \pm 2.74 \\
(-6.86 \text { to } 3.88)\end{array}$ & - & $32.92 \pm 17.41$ & $\begin{array}{c}3.00 \pm 17.54 \\
(-31.38 \text { to } 37.38)\end{array}$ & - \\
\hline \multicolumn{7}{|l|}{$\begin{array}{l}\text { Protocol } 2 \\
\quad \text { Free living }\end{array}$} \\
\hline Camera & $36.00 \pm 7.88$ & - & 1 & $5.31 \pm 3.90$ & - & 1 \\
\hline SP & $36.16 \pm 7.70$ & $\begin{array}{c}0.16 \pm 0.22 \\
(-0.27 \text { to } 0.59)\end{array}$ & $\begin{array}{c}0.999 \\
(0.997 \text { to } 1.000)\end{array}$ & $5.38 \pm 3.91$ & $\begin{array}{c}0.08 \pm-0.28 \\
(-0.47 \text { to } 0.63)\end{array}$ & $\begin{array}{c}0.997 \\
(0.992 \text { to } 0.999)\end{array}$ \\
\hline AP3 & $35.58 \pm 8.60$ & $\begin{array}{l}-0.42 \pm 1.12 \\
(-2.62 \text { to } 1.78)\end{array}$ & $\begin{array}{c}0.990 \\
(0.969 \text { to } 0.997)\end{array}$ & $5.77 \pm 4.80$ & $\begin{array}{c}0.46 \pm 1.66 \\
(-2.79 \text { to } 3.71)\end{array}$ & $\begin{array}{c}0.928 \\
(0.788 \text { to } 0.977)\end{array}$ \\
\hline AP10 & $35.96 \pm 8.19$ & $\begin{array}{c}0.04 \pm 1.63 \\
(-0.95 \text { to } 1.02)\end{array}$ & $\begin{array}{c}0.981 \\
(0.939 \text { to } 0.994)\end{array}$ & $5.62 \pm 4.54$ & $\begin{array}{c}0.31 \pm 3.54 \\
(-1.83 \text { to } 2.45)\end{array}$ & $\begin{array}{c}0.665 \\
(0.192 \text { to } 0.885)\end{array}$ \\
\hline $\mathrm{AG}$ & $21.94 \pm 15.46$ & $\begin{array}{c}-14.05 \pm 13.30 \\
(-40.12 \text { to } 12.02)\end{array}$ & $\begin{array}{c}0.257 \\
(-0.133 \text { to } 0.652)\end{array}$ & $66.08 \pm 44.92$ & $\begin{array}{c}60.77 \pm 43.02 \\
(-23.55 \text { to } 145.09)\end{array}$ & $\begin{array}{c}0.033 \\
(-0.120 \text { to } 0.331)\end{array}$ \\
\hline
\end{tabular}

$\mathrm{AG}=\mathrm{ActiGraph} \mathrm{GT} 3 \mathrm{X}+\mathrm{AP} 3=\mathrm{ActivPAL}^{3} ; \mathrm{AP} 10=\mathrm{ActivPAL}^{3} ; \mathrm{SP}=$ sitting pad; $\mathrm{ICC}=$ intra-class correlation .

being counted as additional transitions. The AP3 was less able to detect the more precise transitions in the prescribed protocol but performed well during free living. The AP10, which is the default setting for the device, did not accurately measure transitions, indicating that 3 seconds may be more applicable for office workers.

The SP provides a high level of accuracy for mapping small and frequent transitions in desk based employees, even with a slight delay through compression and expansion of the sensor. This makes it an ideal device assessing both sitting time and the number of desk based transitions. Given that it is designed to solely measure desk based sitting, we suggest the SP be used in conjunction with a mobile device, such as the AP, to provide a complete picture of occupational sitting. Used an as adjunct measure, the SP offers three benefits to the researcher. Firstly, it provides highly accurate, context specific sitting data relative to where employees sit the most (i.e. their desks); secondly, the SP is unaffected by non wear time and compliance, which tend to be issues with mobile devices; and thirdly, the SP is capable of providing detailed, real time feedback-it therefore

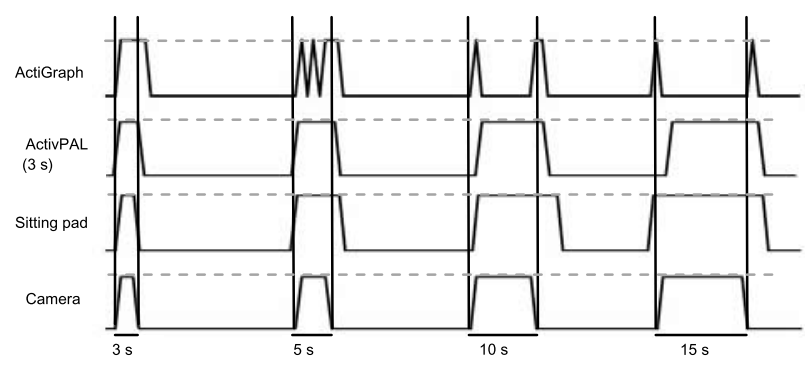

Fig. 2. An example trace from prescribed sitting (indicated by the lower lines) and standing (peaks and dashed lines), for each device and the camera (Australia, 2011).

has the potential to be used as both a measurement and intervention tool.

In considering these benefits, we recognise the strengths and limitations of the present study. There was a small, homogeneous sample, but this allowed for second-by-second camera derived direct observation which was favoured over a larger sample size using indirect and less accurate criterion measures, such as self reported sitting. Another strength was 
that the study was conducted in a real office setting. However, measures were only taken for short periods of time. Future work will build on these initial pilot data by testing the SP in larger groups of office workers for longer periods.

\section{Conclusion}

This study assessed the validity of a new "sitting pad" device to measure occupational sitting. The device provided highly accurate measures of desk based sitting time and transitions. As an adjunct measure, the SP offers novel measurement opportunities to assess links between occupational sitting and health outcomes, and future potential as an intervention tool to reduce and break prolonged sitting at the desk.

Acknowledgments: The authors would like to thank all participants and Dr Geeske Peeters for the statistical advice.

\section{References}

1) Van Uffelen JG, Wong J, Chau JY, et al. Associations between occupational sitting and health risks: a systematic review. Am J Prev Med 2010; 39: 379-88.[PubMed] [CrossRef]

2) Chau JY, der Ploeg HP, van Uffelen JG, et al. Are workplace interventions to reduce sitting effective? A systematic review. Prev Med 2010; 51: 352 6.[PubMed] [CrossRef]

3) Healy GN, Clark BK, Winkler EA, Gardiner PA, Brown WJ, Matthews CE. Measurement of adults' sedentary time in population-based studies. Am J Prev Med 2011; 41: 216-27.[PubMed] [CrossRef]
4) Tremblay MS, Colley RC, Saunders TJ, Healy GN, Owen N. Physiological and health implications of a sedentary lifestyle. Appl Physiol Nutr Metab 2010; 35: 725-40.[PubMed] [CrossRef]

5) Chastin SF, Granat MH. Methods for objective measure, quantification and analysis of sedentary behaviour and inactivity. Gait Posture 2010; 31: 826.[PubMed] [CrossRef]

6) Miller R, Brown W. Steps and sitting in a working population. Int J Behav Med 2004; 11: 21924.[PubMed] [CrossRef]

7) Grant PM, Ryan CG, Tigbe WW, Granat MH. The validation of a novel activity monitor in the measurement of posture and motion during everyday activities. Br J Sports Med 2006; 40: 992-7.[PubMed] [CrossRef]

8) Healy GN, Dunstan DW, Salmon J, et al. Objectively measured light-intensity physical activity is independently associated with 2 -h plasma glucose. Diabetes Care 2007; 30: 1384-9.[PubMed] [CrossRef]

9) Portney LG, Watkins MP. Foundations of clinical research application to practice. Upper Saddle River (NJ): Prentice-Hall; 1993.[PubMed] [CrossRef]

10) Healy GN, Dunstan DW, Salmon J, et al. Breaks in sedentary time-Beneficial associations with metabolic risk. Diabetes Care 2008; 31: 661-6.[PubMed] [CrossRef]

11) Healy GN, Matthews CE, Dunstan DW, Winkler EA, Owen N. Sedentary time and cardio-metabolic biomarkers in US adults: NHANES 2003-06. Eur Heart J 2011; 32: 590-7.[PubMed] [CrossRef]

12) Dunstan DW, Thorp AA, Healy GN. Prolonged sitting: is it a distinct coronary heart disease risk factor? Curr Opin Cardiol 2011; 26: 412-9.[PubMed] [CrossRef] 